Personalidade Acadêmica Homenageada:

Carlos Aurélio Mota de Souza (Universidade Ibirapuera - UNIB)

\title{
A VALORAÇÃO DO DANO MORAL PELO PODER JUDICIÁRIO: A CONCREÇÃO DO DANO EXPERIMENTADO PELA VÍTIMA A PARTIR DA PROPOSITURA DE UM MÉTODO OBJETIVO DE VALORAÇÃO
}

\section{THE VALUATION OF THE MORAL DAMAGE BY THE JUDICIARY POWER: THE CONCRETION OF THE DAMAGE EXPERIENCED BY THE VICTIM FROM THE PROPOSITION OF AN OBJECTIVE METHOD OF VALUATION}

\section{CLAYTON REIS}

Doutor em Direito pela Universidade Federal do Paraná (1999). Mestre em Direito pela Universidade Federal do Paraná (1996). Bacharel em Direito pela Faculdade de Direito de Curitiba (1970). Magistrado em Segundo Grau, aposentado, do TJPR. Professor na Escola da Magistratura do Paraná e pertence ao Corpo Docente Permanente do Programa de Mestrado em Direito Empresarial e Cidadania do UNICURITIBA. Realizou estágio Pós-doutoral na Faculdade de Direito da Universidade de Lisboa-Portugal (2012-2013).

\section{DEBORA CRISTINA DE CASTRO DA ROCHA}

Advogada, graduada em Direito pela Faculdade de Direito de Curitiba - UNICURITIBA, especialista em Direito e Processo do Trabalho e em Direito Constitucional pela Academia Brasileira de Direito Constitucional, pós-graduanda em Direito Imobiliário pela Escola Paulista de Direito e Mestranda em Direito Empresarial e Cidadania pelo UNICURITIBA, professora de Direito e Processo do Trabalho, pesquisadora do CNPQ pelo Centro Universitário Curitiba nos grupos de pesquisa "Reforma Trabalhista" e "Responsabilidade e Função Social da Empresa", Presidente da Comissão de Direito 
Personalidade Acadêmica Homenageada:

Carlos Aurélio Mota de Souza (Universidade Ibirapuera - UNIB)

Imobiliário OAB/SJP, Vice-Presidente da Comissão de Fiscalização, Ética e Prerrogativas OAB/SJP e integrante da Comissão de Direito Imobiliário OAB/PR.

\section{EDILSON SANTOS DA ROCHA}

Pós-graduando em Direito Imobiliário pela Escola Paulista de Direito. Graduando em Direito pela Faculdade da Indústria; Graduado em Tecnologia em Fabricação Mecânica pelo Ensitec. Pesquisador CNPQ pelo Centro Universitário Curitiba.

\section{RESUMO}

Buscar-se á mediante a pesquisa qualitativa na doutrina e jurisprudência e ainda sob uma perspectiva argumentativa indutiva, uma proposta de valoração do "dano moral", no intento de se desenvolver um método valorativo que possa nortear a magistratura, fortalecer a doutrina e amparar a jurisprudência, com vistas à sistematização dos critérios e parâmetros que presidirão a indenização por danos morais, evitando-se que a compensação em pecúnia venha a se transformar em arbitrariedade, o que culminaria com um colapso completo dos princípios básicos do Estado Democrático de Direito. Para tanto, trazer-se á uma análise acerca do reconhecimento histórico do instituto, os métodos e critérios utilizados e por fim discorrer-se-á sobre a proposição de um método objetivo de valoração como meio de concreção do dano como forma de mitigar o risco da tarifação judicial e alcançar a tão almejada reparação integral.

PALAVRAS-CHAVE: Responsabilidade Civil; Dano Moral; Valoração do Dano Moral; Direitos da Personalidade; Dignidade da Pessoa Humana.

\section{ABSTRACT}

It will be sought through the quantitative and qualitative research in doctrine and jurisprudence and also from a logical-deductive argumentative perspective, a proposal of valuation of the "moral damage", in the attempt to develop a value method that can 


\section{Personalidade Acadêmica Homenageada:}

Carlos Aurélio Mota de Souza (Universidade Ibirapuera - UNIB)

guide the judiciary, strengthen the doctrine and support the jurisprudence, with a view to systematizing the criteria and parameters that will preside the indemnification for moral damages, avoiding that the compensation in pecunia will turn into arbitrariness, which would culminate with a complete collapse of the basic principles of the Democratic State right. In order to do so, we shall analyze the historical recognition of the institute, the methods and criteria used and finally discuss the proposition of an objective valuation method as a means of concretizing the damage as a way to mitigate the risk of legal fees and achieve the long-awaited full reparation.

KEYWORDS: Civil Liability; Moral Damage; Valuation of Moral Damage; Personality Rights; Dignity of the Human Person.

\section{INTRODUÇÃO}

O tema da responsabilidade civil em nossa sociedade é um dos mais significativos e recentes do direito contemporâneo. As grandes alterações que vêm ocorrendo no direito brasileiro, a posteriori ao positivismo jurídico e da observação de novos preceitos do direito constitucional, abalaram profundamente o nosso ordenamento, considerando-se as características dos direitos e dos bens tutelados que compõem a temática epistemológica desse ramo da ciência jurídica.

Nesse sentido a abordagem da responsabilidade civil e mais especificamente o dano moral, está intrinsicamente ligada à proteção jurisdicional dos princípios constitucionais basilares da Republica Federativa do Brasil, mas muito, além disso, o direito à vida digna, coadunável com a condição humana e suscetível de lhe oportunizar o acesso aos atrativos mínimos da sociedade.

O dano moral é assunto antigo na história, já ensaiado até mesmo no Direito Romano. Contudo, sua longa subsistência, permanentemente fora dilema de incalculáveis discussões, a começar por sua concepção até sua reparação, denotase, portanto que o ramo da responsabilidade civil é matéria de suma relevância no Direito, e mesmo com o passar dos anos, o dano extrapatrimonial ainda é motivador 
Personalidade Acadêmica Homenageada:

Carlos Aurélio Mota de Souza (Universidade Ibirapuera - UNIB)

de discussões, devido ao não estabelecimento de critérios mais precisos para a fixação quantum indenizável.

Todavia caber ao magistrado tal valoração, devendo esta ser disciplinada com zelo, com respeito aos princípios que regem o Direito, assim como semelhantemente devem ser considerados todo a perspectiva e peculiaridades do caso concreto, assim não deve o magistrado aplicar a sanção da indenização por dano moral de forma generalizada para tanto, ou por outro lado, indiscriminadamente deixar de aplicar a referida penalização, pois inúmeros são os fatores que devem ser considerados no caso concreto, entretanto não há no ordenamento jurídico uma metodologia para ponderação dos critérios.

Assim, o que se busca é uma discussão acerca da necessidade de sistematização do método de valoração, em que pela sistematização proposta o Magistrado deverá se valer obrigatoriamente de todos os critérios de forma sistematizada, ou seja, não basta simplesmente fundamentar sua decisão citando os critérios, sem ao menos enfrenta-los nas suas minucias em aplicação ao caso concreto, ou seja, o que busca é que todos os critérios objetivos e subjetivos sejam enfrentados objetivamente pelo Magistrado, buscando se assim a efetividade dos princípios da proporcionalidade e razoabilidade no processo de valoração do dano moral.

\section{CONTEXTO HISTÓRICO DO DANO MORAL}

De fato, já se verificava a tratativa acerca do tema dano moral no Código de Hamurabi, na Babilônia, acerca de 2.000 anos antes de Cristo, em que conjuntamente ao desagravo "olho por olho, dente por dente", facultava-se, igualmente, a compensação da lesão por intermédio da remuneração de determinado montante pecuniário, autorizando aos teóricos predizerem, nessa situação, a existência primária 
Personalidade Acadêmica Homenageada:

Carlos Aurélio Mota de Souza (Universidade Ibirapuera - UNIB)

da concepção que sobreveio hodiernamente, na "teoria da compensação econômica, satisfatória dos danos extrapatrimoniais". 1

Um fragmento curioso do §224 do livro VIII do Código de Manu, outorgava o rei em pessoa a decretar multa acentuada a pessoa que oferecesse em casamento, sem comunicado prévio ao interessado, uma "donzela com defeitos", com relação ao Hinduísmo, as hipóteses de sanções pecuniárias para certas condutas demonstravam-se como inquestionáveis ofensas deontológicas. ${ }^{2}$

O dano moral e sua posterior indenização deparavam-se em limitações estabelecidas no $§ 9^{\circ}$ da Tábua VII da Lei das XII Tábuas (Lex Duodecim Tabularum) em que depreendia que "aquele que causar dano leve indenizará 25 asses", eis que inteligível era a Lei, abrangia, notoriamente a amplitude reparadora ao prescrever o famigerado axioma de que "se alguém causa dano premeditadamente, que o repare". ${ }^{3}$

De acordo com certos doutrinadores, a Lex Aquilia ostentava uma percepção acerca do dano moral, à medida que avaliada congruentemente, não obstante ordinariamente exprimir que se aludia tão somente à reparação dos danos corpóreos. Augusto Zenun é o preeminente apoiador dessa proposição e preconiza que a clássica disposição da lei aquiliana, alicerçada sobre a imputação elementar, presumia arbítrio sincrético de identificação do nexo de causalidade entre o fato do transgressor e a ofensa, desconsiderando se o dolo nos casos de furto, roubo e injúria. Exemplifica o doutrinador que, se o furto, fosse reparado com pena proporcional, haveria a possibilidade de esta ser imaterial. ${ }^{4}$

O Direito Romano, seguramente, sem maiores níveis de estruturação, antevia diversas conjecturas, em que outorgava tutela a interesses extrapatrimoniais mediante reparação monetária. Destarte, indubitavelmente que ele não culpabilizou, não

\footnotetext{
1 SILVA. Wilson Melo da. O dano moral e sua reparação. Rio de Janeiro: Forense, 1969, p. 253.

2 SILVA, Américo Luís Martins da. O dano moral e a sua reparação civil. São Paulo: Revista dos Tribunais, 1999 , p. 66.

3 ZENUN, Augusto. Dano moral e sua reparação. 3. ed. Rio de Janeiro: Forense, 1995, p. 6.

4 ZENUN, Augusto. Dano moral e sua reparação. 3. ed. Rio de Janeiro: Forense, 1995, p. 9.
} 
Personalidade Acadêmica Homenageada:

Carlos Aurélio Mota de Souza (Universidade Ibirapuera - UNIB)

denegou o interesse moral e, de maneira oposta, o consentiu na medida em que o período social era com ele coadunável. ${ }^{5}$

Em Roma a jurisprudência chegou à concepção de que na existência humana, a ideia de valor não limitava-se a apenas a valores monetários, diversamente existem, além do dinheiro, demais bens aos quais o ser humano civilizado outorga um valor e que necessitam ser tutelados pelo direito. ${ }^{6}$

Demonstrou-se intensa, a elaboração da tese da reparação integral do dano moral, no transcorrer da história do direito moderno. A pertinência moral da outorga de um valor à dor era a mais valorosa e persistente recusa dos que não a aceitavam. Destarte, unicamente admitia-se reparação para ofensas imateriais no momento em que, para certas e determinadas circunstâncias, sucedesse prévia e expressa hipótese de punição civil em pecúnia.

Ocorrera um aumento significativo da linha dos partidários dos direitos fundamentais, posterior ao descobrimento dos denominados direitos de personalidade, do qual em seu meio evidenciou-se lugar de proeminência a integral reparabilidade das ofensas à personalidade, no âmbito extrapatrimonial. Numerosas legislações, em inúmeros países supuseram deliberações tutelares na salvaguarda de imagens, de direitos autorais, etc. O dano moral em 1942, finalmente passou a integrar o novo Código Civil Italiano.

O Código Civil Brasileiro de 1916 em seu artigo 159 dizia respeito ao dano moral, no entanto o entendimento jurisprudencial e doutrinário, dizia que o dano moral exclusivamente seria indenizável à medida que ocasionasse por si reflexos danosos financeiros ao ofendido, não encontrando-se, por conseguinte reparável o dano moral sem consequência de ordem material.

Somente após os insistentes reclamos doutrinários, que acabaram despertando os magistrados de sua inércia, constrangendo-os a enfrentar com maior empatia a nova práxis social que se evidenciava; promovendo-se naquele momento

\footnotetext{
${ }^{5}$ MENDONÇA, Manuel Inácio Carvalho de. Doutrina e prática das obrigações ou tratado geral dos direitos de crédito. 4. ed. aum. e atual. pelo juiz José de Aguiar Dias. Rio de Janeiro: Revista Forense, 1956, t. II, n. 478, p. 58.

6 MAZEAUD, Henri; MAZEAUD, Leon. Traité Théorique et Pratique de la Responsabilité Civile Délictuelle et Contractuelle. 3. ed. Paris: Recueil Sirey, 1938, vol. I, p. 3.663.
} 
Personalidade Acadêmica Homenageada:

Carlos Aurélio Mota de Souza (Universidade Ibirapuera - UNIB)

em nossos tribunais em todos os graus de jurisdição "um processo revisionalista da mea culpa", influenciado na indispensabilidade de uma tutela mais abrangente dos interesses morais, tão incisivamente lesados pelas circunstâncias da sociedade civilizada?

Com o advento da Constituição Federal de 1988, por fim, se fez presente o enunciado do preceito geral que cessou às dubiedades e hesitações dos tribunais (art. $5^{\circ}$, V e X). Finalmente, o Código Civil de 2002 recepcionou dogmaticamente a reparabilidade do dano moral (art. 186).

O individuo que provoque um mal injustificável a outro há de indenizar o ofendido, não importando o tipo de ofensa, pois hodiernamente está inabalavelmente estabelecida a integral e unitária tese da reparação, independentemente do dano civil, seja ele patrimonial ou extrapatrimonial. ${ }^{8}$

Disciplina o Código Civil (art. 944) que o regime indenizatório é o da reparação integral, no que tange à dimensão da reparação do dano (material ou moral), ou seja, deve proporcionar ao ofendido à reposição em condição correspondente a em que estava antes da ocorrência do fato danoso. Teoricamente, essa compensação pode se dar de duas formas: (i) in natura, a partir do restabelecimento do próprio bem no patrimônio do ofendido ou por sua permutação por objeto análogo; ou (ii) por reparação monetária, constituído em remuneração de soma proporcional aos infortúnios do ofendido.

\section{REPARABILIDADE DO DANO MORAL}

Necessário o assentamento de parâmetros na definição do montante da reparação, como método de se obter a reparação integral e exata da ofensa moral. Do modo que na reparação por dano moral, o que se ressarce é um dano provocado

7 CAHALI, Yussef Said, Dano Moral - 3. ed. São Paulo: Revista dos Tribunais, 2005, p.52.

8 THEODORO JÚNIOR, Humberto. Dano moral. 8.ed. revista, atualizada e ampliada. Rio de Janeiro: Forense, 2016, p. 04. 


\section{Personalidade Acadêmica Homenageada:}

Carlos Aurélio Mota de Souza (Universidade Ibirapuera - UNIB)

à intimidade da pessoa, evidentemente torna-se impossível uma exatidão no cálculo do dano.

A indenização por dano moral tem como característica a função satisfativa, com o intento de atenuar o dissabor experimentado pelo ofendido, ou reprimir as repercussões do dano propiciado, distintivamente da função de equivalência pretendida na indenização do dano material.

Sérgio Cavalieri Filho ${ }^{9}$ dispõe que, substitui-se a definição de equivalência, característica do dano material pelo da compensação que se aufere, minora-se de forma indireta as implicações do dissabor. Em contrapartida, não se pode desconsiderar a imprescindibilidade de se determinar uma sanção ao responsável pelo dano moral, para não passar despercebida a transgressão e, desta maneira encorajar novas agressões. A indenização subsistirá do mesmo modo como uma categoria de pena irrefutável em favor da vítima.

Além desta atribuição e às vezes a contrassenso a esta, alguns doutrinadores sustentam que a reparação incumbe-se de uma função punitiva, pois exerce, com relação ao agente do dano, uma penalidade mediante a subtração dos bens do infrator, não devendo este ficar isento perante o dano proporcionado.

René Savatier ${ }^{10}$ esclarece que imputar ao ofendido o propósito de reparar um dissabor tão grande mediante uma satisfação tão vulgar, seria torna-la desprezível. É indispensável, pois, motivo distinto para a sanção pecuniária. Ela vem a ser, por conseguinte, uma pena privada. Imersos em um instinto de justiça e estabilidade, os tribunais se denegam a tolher de sanção o ato causador que tenha motivado um dano moral crítico.

O dano moral é uma ofensa que lesiona intimamente vítima, perturbando seu ânimo. Para a reparação de um dano desse tipo, descabe-se falar em reparação por equivalência, como se verifica no dano material, em virtude de que os bens abalados pelo dano moral, por tratarem-se de sentimentos e estados subjetivos, não são susceptíveis de valoração equivalente ao prejuízo. Remanesce, à vista disso, a

${ }^{9}$ CAVALIERI FILHO, Sérgio . Programa de responsabilidade civil - 11. ed. - São Paulo : Atlas, 2014, p. 85.

10 SAVATIER apud ANDRADE, 2009, p.148. 


\section{Personalidade Acadêmica Homenageada:}

Carlos Aurélio Mota de Souza (Universidade Ibirapuera - UNIB)

obtenção de um montante que aproveite, dentro da razoabilidade e proporcionalidade, amenizar o dissabor do dano do ofendido, bem como punir o agente causador da ofensa por seu ato ou omissão.

No que tange ao dano moral, possível é considerar-se dos dois modelos de reparação. Observa Karl Larenz que o dano subjetivo pode ser recompensado ao passo que isso seja realizável mediante a reparação in natura: isso dispõe especialmente nas hipóteses de desagravo público de manifestações publicamente manifestadas, idôneas para infringir a honra de outrem ou para deteriorar sua credibilidade ( $\$ 824$ do BGB). ${ }^{11}$

Pontes de Miranda, nada obstante, dispõe acerca do dano imaterial, que a reparação in natura é, quase que em todo o tempo, improvável, acreditando, de outro modo, pode-se permitir, em outras hipóteses, que o dano moral ou se compensa por um ato que o suprima, desagravo do difamador ou do injuriante, ou pelo pagamento do que foi considerado reparador. ${ }^{12}$

Muito embora, recepcionando a tese da factível reparação natural na esfera das lesões extrapatrimoniais, o STJ depreende que a reparação, em si mesmo, não se evidencia satisfatória para a compensação dos danos sofridos pelo lesado, da forma integral exigida pelo art. 944 do CC. Por esse motivo ter deduzido o acórdão pela determinação cumulada da disseminação do ato de reparação com o ressarcimento monetário. ${ }^{13}$

Do novo estabelecimento, em nosso ordenamento jurídico, da integralidade de reparabilidade da lesão extrapatrimonial, provieram inumeráveis e impasses substanciais, de caráter teórico e prático, alguns dos quais até então não totalmente sanados.

11 LARENZ, Karl. Derecho de obligaciones. Madrid: Editorial Revista de Derecho Privado, 1959, t. I, § 14, p. 229.

12 PONTES DE MIRANDA, Francisco Cavalcanti. Tratado de direito privado. Rio de Janeiro: Borsoi, 1959, v. 54, § 5536, p. 61.

${ }^{13}$ STJ, 3 ${ }^{\mathrm{a}}$ T., REsp 959.565/SP, Rel. Min. Paulo de Tarso Sanseverino, ac. 24.05.2011, DJe 27.06.2011. 
Personalidade Acadêmica Homenageada:

Carlos Aurélio Mota de Souza (Universidade Ibirapuera - UNIB)

\section{OS MÉTODOS DE VALORAÇÃO UTILIZADOS PELO PODER JUDICIÁRIO}

\subsection{TARIFAÇÃO LEGAL}

O experimento brasileiro, de tarifação legal da reparação por dano extrapatrimonial não se demonstrou oportuna. Trata-se de parâmetro para a mensuração da indenização por dano moral a partir da tarifação legal, constituindo-se na previsão pelo legislador do importe da indenização proporcional a certos eventos danosos.

O Código Civil de 1916 previa que, não sendo possível evidenciar perda material, a determinação da indenização deveria ter correspondência com o "dobro da multa no grau máximo da pena criminal respectiva". Os casos de tarifamento legal estavam dispostos em seu artigo 1550 previa a ofensa à liberdade pessoal e no artigo 1547 a injúria e a calúnia.

Sem embargo, em virtude do valor incoerente atingido, o Superior Tribunal de Justiça firmou entendimento, fundamentando-se nos pressupostos regimentais da proporcionalidade e da razoabilidade, na orientação da desutilidade do tarifamento legal indenizatório. Até mesmo porque a leva consumada pelo legislador do Código Civil de 1916 à lei penal era anterior ao mesmo Código Penal de 1940, mais ainda com relação a reforma penal de 1984.

A jurisprudência passou a ter o entendimento de que os juízes deveriam determinar a indenização a partir do arbitramento equitativo, que foi do mesmo modo a direção adotada pelo legislador do Código Civil de 2002, ao conceber a expressão da premissa normativa do parágrafo único do art. 953, o qual dizia que "se o ofendido não puder provar prejuízo material, caberá ao juiz fixar, equitativamente, o valor da indenização, na conformidade das circunstâncias do caso".

A Lei de Imprensa (Lei 5250/67) nos artigos 49 e segs. trazia outra hipótese muito importante da tarifação legal indenizatória encontrada no Direito brasileiro, a referida lei regulamentava a responsabilidade civil em relação ao individuo que, no desempenho da permissão de exteriorização do pensamento e da informação, mediante culpa ou dolo, causasse danos materiais e morais. Estabelecia ainda, em 
Personalidade Acadêmica Homenageada:

Carlos Aurélio Mota de Souza (Universidade Ibirapuera - UNIB)

seu art. 54, em relação aos danos materiais que a indenização teria por propósito reparar o lesado ao status quo ante ao ato ilícito, recepcionando, deste modo, conclusivamente o princípio da reparação integral.

Contudo, com relação aos danos extrapatrimoniais, estipulava, no art. 51, uma limitação indenizatória, que, para o jornalista profissional, oscilava entre dois e vinte salários mínimos, de acordo com a magnitude do ato ilícito experimentado. No que diz respeito às corporações jornalísticas, o montante indenizatório, segundo estabelecido pelo art. 52, poderia elevar-se em até dez vezes o valor assinalado na norma antecedente. Desse modo, o montante ótimo da reparação por danos extrapatrimoniais por ilicitudes civis tipificadas pela Lei de Imprensa poderia atingir duzentos salários mínimos.

A congruência da tarifação legal reparatória da Lei de Imprensa passou a ser debatida desde a entrada em vigor da Constituição Federal de 1988, a qual, dentre os direitos e garantias individuais, em seu art. $5^{\circ}$, passou a regulamentar o princípio da livre manifestação do pensamento, ensejando "o direito de resposta proporcional ao agravo, além da indenização por dano material, moral ou à imagem" (inciso V), do mesmo modo que estabeleceu que "são invioláveis a intimidade, a vida privada, a honra e a imagem das pessoas, sendo assegurado direito a indenização pelo dano material ou moral decorrente de sua violação" (inciso X).

Com o advento da Súmula 281 o Superior Tribunal de Justiça se posiciona no sentido de que a indenização por dano moral não se sujeita ao tabelamento previsto na Lei de Imprensa, demonstra-se, consequentemente que o posicionamento daquele tribunal, posteriormente uma profunda discussão, fundamentado no que fora assentado nos referidos dispositivos normativos do art. 5을 incisos $\mathrm{V}$ e $\mathrm{X}$ da Constituição Federal de 1988.

Nesse sentido, foram revogadas todas as limitações à indenizabilidade irrestrita dos danos morais motivados por ilicitudes praticadas a partir da imprensa, permitindo se empregar tanto as hipóteses de tarifação legal indenizatória, mencionadas nos artigos 49 a 52, outrossim, o prazo decadencial de três meses assentado pelo art. 56 da Lei da 5250/67. 


\section{Personalidade Acadêmica Homenageada:}

Carlos Aurélio Mota de Souza (Universidade Ibirapuera - UNIB)

Dessa forma, fundamentada na normativa constitucional, a jurisprudência resultou por proclamar a determinação da indenização plena das lesões materiais e morais ocasionadas mediante a imprensa.

Nas hipóteses referidas de tarifamento legal, sejam as mencionadas pelo Código Civil de 1916, sejam aquelas estabelecidas pela Lei de Imprensa, que eram as mais significativas de nosso ordenamento jurídico para a reparação pelas lesões extrapatrimoniais, entendeu-se pela sua total desaprovação pela jurisprudência do STJ, fundamentado no axioma da razoabilidade.

\subsection{ARBITRAMENTO EQUITATIVO}

Em decorrência da impraticabilidade de uma indenização pecuniária que repare plenamente a lesão ao bem ou interesse jurídico ofendido, a resolução é uma indenização com natureza satisfatória, que não guardará uma conexão de igualdade exata com o dano extrapatrimonial, mas que deverá ser feita de forma equitativa.

A partir da normativa do artigo 1226 do Código Civil italiano, Valentina di Gregório, evidencia a presença da equidade integrativa, eis que a norma outorga poderes ao magistrado para efetuar equitativamente a avaliação do dano (danos futuros, lucros cessantes, artigo 2056), até mesmo dos danos morais, nos termos subsequentes:

Art. 1226 (Valutazione equitativa del danno): "Se il danno non può essere provato nel suo preciso ammontare, è liquidato dal giudice com valutazione equitativa (art. 2056).

A Corte de Cassação italiana entende que não se trata de arbitrar equitativamente, em consonância com o facultado pelo artigo 114 do Código de Processo Civil italiano para determinadas hipóteses fáticas, mas de arbitramento equitativo da lesão, tendo em conta os seus parâmetros objetivos, a sua magnitude, 
Personalidade Acadêmica Homenageada:

Carlos Aurélio Mota de Souza (Universidade Ibirapuera - UNIB)

o ofendido, a situação financeira das partes, tornando incontestável que, não obstante a quantificação seja subjetiva, deve ser fundamentada em critérios objetivos ${ }^{14}$.

No Direito Português, Almeida Costa ${ }^{15}$ alerta para perspectiva similar, proclamando, com fulcro no artigo 496, n. 3 , do Código Civil português, que a indenização proporcional aos danos extrapatrimoniais deve ser fundamentada segundo parâmetros de equidade, cuidando-se não só a extensão e a seriedade dos danos, todavia do mesmo modo ao grau de culpabilidade do ofensor, à sua situação econômica e de modo igual a do ofendido, assim como todas as demais hipóteses que colaborem para uma resolução equitativa. Adverte tão somente que o referido critério não se confunde com a minoração da responsabilidade disposta no artigo 494 do Código Civil português, equivalente ao parágrafo único do art. 944 do Código Civil brasileiro de 2002, eis que a referida norma pode ser aplicada exclusivamente nos casos de mera culpa, no mesmo momento em que o artigo 496, n. 3, demonstra-se apropriado ainda que o agente tenha agido com dolo.

Em nosso ordenamento pátrio, contudo não dispor de norma geral para o arbítrio da reparação por dano moral, análogo ao artigo 496, n. 3, do Código Civil português, tem-se a regra específica do parágrafo único do artigo 953 do Código Civil brasileiro de 2002, já mencionada, que, no caso de lesões contra a honra, não sendo crível comprovar prejuízo patrimonial, outorga poderes ao magistrado para o arbitramento, com fundamento na equidade, o montante da indenização em consonância com as nuances do caso concreto.

$\mathrm{Na}$ ausência de regramento especifico, a referida norma pode ser estendida, por correspondência, às outras hipóteses de danos sem caráter econômico (LICC, art. $4^{\circ}$ ). Diante do referido preceito, Menezes Direito e Cavalieri Filho, exteriorizam sua anuência com a disposição traçada pelo Min. Ruy Rosado de que a equidade é o critério que o Código Civil brasileiro em seu artigo 953, concedeu ao magistrado para a valoração da indenização ${ }^{16}$.

${ }^{14}$ GREGORIO, Valentina di. La valutazione equitativa del danno. Padova: Cedam, 1999, p. 4.

${ }_{15}$ COSTA, Mário Júlio Almeida. Direito das obrigações. Coimbra: Almedina, 2004, 554.

${ }^{16}$ DIREITO, Carlos Alberto Menezes; CAVALIERI FILHO, Sérgio. Comentários ao novo Código Civil : da responsabilidade civil, das preferência e privilégios creditórios. Rio de Janeiro: Forense, 2004. v. 13, p. 348. 


\section{Personalidade Acadêmica Homenageada:}

Carlos Aurélio Mota de Souza (Universidade Ibirapuera - UNIB)

O juiz da ação indenizatória em pessoa, na própria decisão em que verifica a materialidade da ilicitude, deve efetivar ao arbítrio da reparação. O obstáculo ensejado pelo artigo 946 do Código Civil brasileiro de 2002, quando determina que, se a obrigação for indefinida e não estiver prevista na lei ou em contrato para determinação da indenização, esta deverá ser arbitrada na forma preconcebida pela legislação processual, de outro modo, por liquidação de sentença por artigos e por arbitramento conforme artigo 603 a 611 do Código de Processo Civil brasileiro supera-se com a aplicação analógica do parágrafo único do artigo 953 do Código Civil brasileiro de 2002, que determina o arbitramento equitativo da reparação para o dano moral.

Destarte, segue-se a prática perdurável, em nosso ordenamento jurídico, de imediatamente arbitrar na própria decisão (sentença ou acórdão) que declara procedente o pleito principal, a reparação por lesão extrapatrimonial, abstendo-se de que o juiz, futuramente, tenha de repisar inutilmente a apreciação da prova, ademais em se permitir que o tribunal, ao averiguar eventual rediscussão da matéria em sede recursal, avalie imediatamente o valor indenizatório fixado.

$\mathrm{O}$ autorizativo legal para $\mathrm{O}$ arbitramento por equidade não reproduz 0 consentimento do legislador ao magistrado de um poder arbitrário, pois a reparação, além de ser fixada com razoabilidade, deve ser adequadamente fundada com a prescrição dos critérios empregados. Diante disso, constata-se que o estabelecimento de quais são os critérios razoavelmente objetivos a serem utilizados pelo magistrado nessa operação de arbitramento da indenização por dano extrapatrimonial, tem sido uma tarefa árdua para a doutrina e a jurisprudência.

\subsection{PONDERAÇÃO DAS CIRCUNSTÂNCIAS DO EVENTO DANOSO}

$\mathrm{Na}$ fraseologia de Karl Engisch, o arbítrio fundado na equidade da indenização institui um procedimento de "concreção individualizadora", propondo que todas as circunstâncias específicas do caso sejam abalizadas para a definição das suas resultantes jurídicas ${ }^{17}$.

17 ENGISCH, Karl. La idea de concrecion en el derecho y en la ciência jurídica atuales. Tradução de Juan José Gil Cremades. Pamplona: Ediciones Universidade de Navarra, 1968, p. 389. 
Personalidade Acadêmica Homenageada:

Carlos Aurélio Mota de Souza (Universidade Ibirapuera - UNIB)

Na valoração da reparação por danos morais, as circunstâncias preeminentes quantificadas pelas deliberações judiciais têm-se a denominada operação de concreção individualizadora, em que têm a intensidade do sofrimento da vítima, a eventual culpa concorrente da vítima, a gravidade do fato em si, a culpabilidade do agente responsável, a condição econômica, política e social das partes.

Maria Celina Bodin de Moraes classificou como reconhecidos os dados subsequentes para a avaliação do dano extrapatrimonial: a situação econômica do transgressor, o grau de culpabilidade e a intensidade do dolo, a natureza a gravidade e a repercussão da ofensa ( extensão do dano); as condições pessoais do ofendido (posição social, política, econômica) e a intensidade do sofrimento experimentado pela vitima ${ }^{18}$.

Em precedentes do Superior Tribunal de Justiça, vem sendo acolhida a probabilidade de atenuação da reparação na eventualidade de culpa concorrente do devedor, consoante se conclui nos precedentes REsp 712.591/RS ${ }^{19}$, AG $1172750 / \mathrm{SP}^{20}$ e REsp 632.704/RO21. Revela-se adequada essa tendência, eis que, em sendo dever do juiz exercer um arbitramento equitativo da reparação, não pode deixar igualmente de mensurar essa circunstância significativa, que é a culpa concorrente do devedor.

As referidas circunstâncias judiciais compõem significativas ferramentas para amparar o magistrado no respaldo jurídico da reparação por dano moral, mostram um impedimento de execução, que obstaculiza a sua aplicação. Sobrevém que, na responsabilidade civil, diversamente do Direito Penal, inexistem indicadores mínimos e máximos para delimitar a aferição da reparação.

Consequentemente, a despeito de as circunstâncias judiciais moduladoras serem significativos fundamentos de concreção na execução judicial de avaliação da reparação por danos. Atualmente no Direito brasileiro, evidencia-se improvável um tarifamento ou tabelamento da indenização para os prejuízos morais, pois a

18 MORAES, Maria Celina Bodin de. Danos à Pessoa Humana. Rio de Janeiro: Renovar, 2003, p. 29.

19 STJ, 3를. REsp 712.591/RS, rel.: Min. Nancy Andrighi, j. 16/11/2006, Dje 04/12/2006.

20 STJ, 4ㄹ T., AG 1172750/SP, Rel. Min. João Otávio de Noronha, DJe 06.09.2010.

21 STJ, 4ํㅜ T., REsp 632.704/RO, Rel. Min. Jorge Scartezzini, Dj. 01/02/2006. 


\section{Personalidade Acadêmica Homenageada:}

Carlos Aurélio Mota de Souza (Universidade Ibirapuera - UNIB)

aprovação da sua reparação é muito recente, sendo indispensável maior maturação dos critérios de avaliação pela comunidade jurídica.

É preciso ter cautela, até mesmo, com o tarifamento judicial, que sorrateiramente começa a acontecer, a despeito de não ser admitido expressamente por nenhum julgador, na determinação das indenizações por danos morais de acordo com precedentes jurisprudenciais, em se considerando apenas o bem jurídico atingidos.

\subsection{BEM JURÍDICO LESADO}

A avaliação do bem ou interesses jurídicos lesados pelo evento danoso, como vida, integridade física, liberdade, honra, constitui um critério muito aplicado na atividade judicial, constituindo-se em afixar as reparações por danos morais em consonância com os precedentes que julgaram fatos similares.

Judith Martins-Costa sugeriu o referido critério por perceber que, o arbítrio do magistrado na apreciação do dano deve ser efetivado em obediência à autoridade da cláusula geral do artigo 944 do Código Civil brasileiro, norma fundamental em se tratando de indenização ${ }^{22}$.

As normas gerais de reparação devem, portanto, obedecer a regra da reparação integral de acordo com o seguinte esclarecimento de Stoco: "Cuidando-se de dano material, incide a regra da restitutio in integrum do artigo 944 do Código Civil brasileiro, nessa conformidade 'a indenização mede-se pela extensão do dano". ${ }^{23}$

O critério alusivo ao bem jurídico ofendido é substancialmente aplicado na prática judiciária brasileira, a despeito de não ter sido categoricamente assentido pelos magistrados e tribunais, valoriza o bem ou interesse jurídico lesado (vida, liberdade, honra, integridade física) para fixar as indenizações por danos morais em consonância com os precedentes que julgaram casos similares.

22 MARTINS-COSTA, Judith. Comentários ao novo Código Civil : do inadimplemento das obrigações. Rio de Janeiro: Forense, 2003 . v. 5, t.1-2, p. 351.

${ }^{23}$ STOCO, Rui. Tratado de Responsabilidade Civil. 6 ed. São Paulo: Editora Revista dos Tribunais, 2004, p. 1184. 
Personalidade Acadêmica Homenageada:

Carlos Aurélio Mota de Souza (Universidade Ibirapuera - UNIB)

Essa metodologia apresenta adversidades de ordem prática, sendo o primeiro deles o fato de ser empregado individualmente por cada unidade jurisdicional (juiz, câmara ou turma julgadora), sucedendo escassa permeabilidade para as resoluções adotadas pelos tribunais.

Outra questão se encontra no risco de sua aplicação com exagerada intransigência, encaminhando a um malquisto tarifamento judicial das reparações por prejuízos morais, proporcionando um engessamento da prestação jurisdicional e transfigurando o seu livre arbítrio deixara de lado a necessidade de se obter a concreção para se tornar um simples procedimento de subsunção.

A tarifação judicial, tal como o legal, não se manifesta coadunável com o preceito da plena reparação que tem, como uma de suas principais finalidades, a exigência de apreciação efetiva da indenização, inclusive por prejuízos morais.

$\mathrm{Na}$ França, a jurisprudência interpreta metodicamente que a avaliação dos danos é uma questão fática, valorizando o poder dos magistrados na sua apreciação e criticando os tentames de tarifamento de indenizações ${ }^{24}$. Em nosso ordenamento, a jurisprudência do STJ tem prestigiado as indenizações por danos morais arbitradas pelas instâncias inferiores uma vez que atendam a um método coerente, não podendo ser desmedidamente superiores ou ínfimas, conforme será explorado ulteriormente.

Em síntese, a apreciação valorativa do bem ou interesse jurídico lesado é um critério relevante, nada obstante deve-se ter a consciência para que não se direcione a um engessamento descomedido das indenizações por prejuízos imateriais, tipificando um malvisto tarifamento judicial com inflexibilidade semelhante ao tarifamento legal.

\subsection{MÉTODO BIFÁSICO PARA O ARBITRAMENTO EQUITATIVO DA INDENIZAÇÃO}

O Superior Tribunal de Justiça adere em muitos julgados, de acordo com seus antecedentes, o método bifásico de valoração da reparação por danos morais, que primeiramente fixa um valor base para a indenização, tendo em vista o interesse

24 VINEY, Geneviève; MARKESINIS, Basil. La Reparation du dommage corporel: Essai de comparaison des droits anglais e français. Paris: Economica, 1985, p. 48. 
Personalidade Acadêmica Homenageada:

Carlos Aurélio Mota de Souza (Universidade Ibirapuera - UNIB)

jurídico lesado, e, por conseguinte analisa a conjuntura do caso, para a fixação do montante da reparação, em atenção à determinação legal de julgamento equitativo pelo magistrado. ${ }^{25}$

Em acórdão da relatoria da Ministra Nancy Andrighi o Superior Tribunal de Justiça, se utilizou do método bifásico para valoração da reparação por danos morais decorrentes do abalo de crédito, cuja ementa foi a seguinte:

\begin{abstract}
Consumidor. Recurso Especial. Cheque furtado. Devolução por motivo de conta encerrada. Falta de conferência da autenticidade da assinatura. Protesto indevido. Inscrição no cadastro de inadimplentes. Dano moral. Configuração. Culpa concorrente. - A falta de diligência da instituição financeira em conferir a autenticidade da assinatura do emitente do título, mesmo quando já encerrada a conta e ainda que o banco não tenha recebido aviso de furto do cheque, enseja a responsabilidade de indenizar os danos morais decorrentes do protesto indevido e da inscrição do consumidor nos cadastros de inadimplentes. Precedentes. - Consideradas as peculiaridades do processo, caracteriza-se hipótese de culpa concorrente quando a conduta da vítima contribui para a ocorrência do ilícito, devendo, por certo, a indenização atender ao critério da proporcionalidade. Recurso especial parcialmente conhecido e nessa parte provido. (Resp 712591/RS,Dje 04.12.2006, Rela. Min. Nancy Andrighi).
\end{abstract}

No caso tratado nesse precedente, o Tribunal de Justiça do Rio Grande do Sul decidira ser cenário de culpa exclusiva da requerente e, consequentemente, não reconheceu a ocorrência de ilicitude causador do dano moral, depois de aceitar a responsabilidade concomitante do banco pelo fato danoso, e investigar o valor arbitrado por danos morais para cenários similares naquele Tribunal, que variavam de 10 a 14 mil reais, a ministra relatora, realizando alusão a dois precedentes, passou a verificar as singularidades do caso, deliberando, então, a indenização 4 mil reais a título de danos morais.

Dos procedimentos considerados o método bifásico tem sido o mais adequado, eis que atende às premissas de um arbitramento equitativo da reparação por danos morais. Apesar disso, ameaça-se a precificação dos direitos da personalidade, na hipótese de se entender que, uma vez verificado o interesse jurídico desrespeitado, servirá o estabelecimento de um montante elementar, desprezando-

25 STJ, 3- Turma, REsp 1.152.541-RS, rel. Min. Paulo de Tarso Sanseverino, j. 13-9-2011, DJ 21-92011. 
Personalidade Acadêmica Homenageada:

Carlos Aurélio Mota de Souza (Universidade Ibirapuera - UNIB)

se outro critério que possa concluir essa fase. É indispensável o preenchimento de outro parâmetro, no intuito de se impossibilitar a inapropriada tarifação do interesse jurídico, sob pena de objetificação do direito da personalidade violado ${ }^{26}$.

\section{PROPOSITURA DE SISTEMATIZAÇÃO DO MÉTOdO DE VALORAÇÃO}

Da análise dos métodos apresentados, tem se em tese que o sistema bifásico é o mais eficaz, pois, a partir de precedentes judiciais análogos classificados em consonância com o interesse jurídico lesado, é feita a ponderação pelo Magistrado, a partir de um arbitramento que considera as circunstancias do caso concreto.

O sistema bifásico dentre os métodos citados é aquele que mais se aproxima da concreção do dano experimentado pela vitima e consequentemente gera uma reparação que mais se aproxima da tão almejada proporcionalidade e razoabilidade. Na mesma linha de raciocínio, se propõe a partir do método bifásico, uma nova metodologia que almeja a sistematização da valoração que deverá ser composta por três fases, assim como no sistema de dosimetria da pena.

Para tanto, o desenvolvimento do método deve se dar por analogia aos critérios e fases utilizados no direito penal, assim, analogamente à subsunção do fato à norma, o referido método fará a subsunção do caso concreto aos precedentes judiciais classificados e subdivididos.

Tais precedentes deverão ser classificados de acordo com o interesse jurídico lesado e circunstâncias do caso concreto, para isso deverá ser feito todo um levantamento quantitativo e qualitativo das indenizações na jurisprudência. A partir do referido levantamento deve ser feita uma média ponderada dos valores mínimos e máximos das indenizações, que, assim como na dosimetria da pena serão referência para o cálculo após a subsunção do caso concreto ao precedente equivalente.

${ }^{26}$ LISBOA, Roberto Senise. Manual de Direito Civil, volume II: obrigações e responsabilidade civil. 3. ed. rev. atual. ampl. São Paulo: Revista dos Tribunais, 2004. Manual de Direito Civil V: obrigações e responsabilidade civil. 6. ed. rev. atual. ampl. São Paulo: Saraiva, 2012, p. 574. 


\section{Personalidade Acadêmica Homenageada:}

Carlos Aurélio Mota de Souza (Universidade Ibirapuera - UNIB)

Clayton Reis ${ }^{27}$ nos traz que o estabelecimento de parâmetros mínimos e máximos não retira a discricionariedade do magistrado, mas sim estabelece uma analise cognitiva do caso concreto, afirmando ainda que os critérios utilizados na sentença criminal não se diferem da sentença cível.

Assim, na primeira fase será subsumido o caso concreto à situação equivalente contida nos precedentes, por isso há que se ter uma classificação precisa e mais detalhada possível, com diversos precedentes classificados, não somente pelo interesse jurídico lesado, mas também pelas circunstâncias em que ocorrera o dano. Busca-se com tal detalhamento, uma maior aproximação entre os casos, para que não haja distorções que poderiam acarretar a perda da eficácia do sistema valorativo.

Ainda na fase inicial, assim como no direito penal, após a subsunção será necessária uma primeira ponderação, seja ela a partir de critérios objetivos ou subjetivos para que seja determinada a indenização base em analogia à pena base do sistema penal, mas que já se torne adequada ao caso concreto, evitando, portanto o risco de se incorrer na tarifação.

Determinado o montante indenizatório inicial, na segunda fase, assim como no sistema penal ao valor base deverão ser aplicadas as agravantes e minorantes a partir dos critérios objetivos e subjetivos, em que, a partir da análise de cada critério, será aumentada ou reduzida a indenização base em percentuais, determinados a partir da ponderação individual de cada critério discricionariamente pelo Magistrado, o que deverá ser feito equitativamente em conformidade com o caso concreto.

Aplicados os critérios objetivos e subjetivos, sejam eles minorantes ou majorantes de acordo com o caso concreto, passar-se à terceira fase, na qual se tem a aplicação dos critérios que serão determinados como causas de aumento ou diminuição, momento esse em que, a indenização poderá ficar abaixo da indenização mínima ou acima da indenização máxima, eis que tais critérios serão determinantes ao valor final da indenização.

Portanto, primeiramente a partir da constatação dos pressupostos básicos da responsabilidade civil com a ponderação dos critérios metodologicamente, poderá se

${ }^{27}$ REIS, Clayton. Avaliação do dano moral / Clayton Reis. Rio de Janeiro, Forense, 2000, p. 103. 


\section{Personalidade Acadêmica Homenageada:}

Carlos Aurélio Mota de Souza (Universidade Ibirapuera - UNIB)

constatar se o transtorno vivenciado pelo ofendido extrapolou o limite da normalidade e consequentemente a transposição da barreira do mero aborrecimento, tornando-se imperioso, portanto, discernir o que é o mero aborrecimento, de quando, efetivamente, ocorre o rompimento do limite da normalidade, ensejador de uma lesão moral passível de compensação.

Há que se considerar, portanto, que o método tem em si o papel de garantir o papel da reparação pecuniária, que se dará a partir da identificação dos critérios para a sua adequada quantificação, a qual se aplicada corretamente trará novas luzes ao sistema jurídico, com vistas a determinar a reparação de modo proporcional à intensidade da dor do ofendido, todavia, ainda como diferencial, a possibilidade de mensuração prévia da intensidade da dor de forma sistemática, mas sem que seja retirado o poder discricionário do Magistrado.

Não obstante, há que se considerar conjuntamente, uma análise correlacionada ao sentido punitivo da indenização, ou seja, o que se busca com a punição. E, portanto, sob o prisma do seu caráter pedagógico, como se determinar um quantum suficiente para evitar a reincidência.

Portanto, no que tange ao arbitrium boni viri do magistrado, tem-se em vista a manutenção de sua discricionariedade para que a este se permita ponderar adequadamente os critérios e princípios basilares que nortearão o magistrado na decisão mais justa.

Nesse sentido, ressalte-se que os critérios deverão ser analisados individualmente após serem subdivididos em positivos e negativos. Os quais por ora, cita-se, a condição econômica, pessoal e social do ofendido; condição econômica do ofensor; grau de culpa; gravidade e intensidade do dano; hipótese de reincidência; compensação pela dor sofrida pelo ofendido; desestímulo da prática delituosa; a impossibilidade de enriquecimento do ofendido, e por fim, a viabilidade econômica do ofensor.

Tem se, portanto, a propositura de um método que busca se valer da jurisprudência de forma minuciosa, classificando-a a partir de uma análise qualitativa, assim como, a determinação dos valores médios indenizatórios a partir de uma análise quantitativa, os quais terão como função de delimitar os valores mínimos e máximos 


\section{Personalidade Acadêmica Homenageada:}

Carlos Aurélio Mota de Souza (Universidade Ibirapuera - UNIB)

para posteriormente serem valorados sistematicamente a partir de critérios objetivos e subjetivos pré-determinados, norteando, portanto, o magistrado na decisão mais justa, em atenção aos princípios da equidade, razoabilidade e proporcionalidade conforme determinação do Código Civil, assim como a reparação integral às lesões exclusivamente extrapatrimoniais, prevista em nossa Carta Magna.

\section{CONCLUSÃO}

Nos tempos atuais, considera-se superada a discussão sobre o cabimento de indenização por danos morais. Todavia, tem-se que a forma como será arbitrada a indenização ainda gera muita controvérsia, tanto na doutrina, quanto na jurisprudência. Pois, diferentemente dos danos materiais, que podem ser quantificados em observância a sua extensão, no caso dos danos extrapatrimoniais o cenário para sua quantificação se revela bem mais complexo.

Desta forma, imprescindível se revela a aplicação de métodos de valoração da reparação levando-se em conta as situações apresentadas no caso concreto, para que assim se tenha uma visão mais nítida das alternativas existentes para a quantificação do dano, de tal sorte que a subjetividade possa contribuir com a sua maior precisão, todavia, sem desprezar os critérios objetivos, que igualmente possuem imensa relevância.

Assim, propõe-se à discussão a aplicação sistematizada dos critérios subjetivos e objetivos ao caso concreto para a fixação do quantum indenizatório, com base na metodologia da dosimetria da pena que analogamente trata de questões tão complexas quanto a aquelas relacionadas ao dano moral.

Diante da complexidade em se mensurar o dano extrapatrimonial, e quase que a sua impossibilidade com base em critérios puramente objetivos é que se faz necessária a sistematização em sua mensuração, devendo conjuntamente ser considerados os critérios subjetivos.

O método proposto trata-se de um sistema objetivo, sistemático, mas que permite o arbitramento judicial, com base na equidade, nos princípios da razoabilidade 
Personalidade Acadêmica Homenageada:

Carlos Aurélio Mota de Souza (Universidade Ibirapuera - UNIB)

e da proporcionalidade e, com análise das condições da vítima e do ofensor, determinar o valor mais adequado para a reparação do dano moral, portanto, sistematizar a aplicação dos critérios com vistas a otimização da valoração tem o intuito de que o instituto dano moral atinja sua eficácia plena, sem que, no entanto o magistrado perca sua capacidade discricionária, prevenindo, por conseguinte a tarifação.

Consequentemente, necessária se faz, portanto, a sistematização na determinação dos critérios objetivos e subjetivos a fim de se vislumbrar a essência do instituto do dano moral, de modo a contribuir com a efetividade da sua natureza jurídica, que tem por premissa essencial a reparação do lesado e a punição do ofensor, sem que essa reparação se torne tão vultosa que consista em uma fonte de enriquecimento, ou ainda, seja tão inexpressiva que se torne ínfima, o que afastaria seu caráter pedagógico-punitivo.

\section{REFERÊNCIAS}

BRASIL. Constituição Federal de 1988. Disponível em: <www.planalto.gov.br/ ccivil_03/.../constituiçao.htm>. Acesso em: 15 mar. 2018.

. Lei no 13.467, de 13 de julho de 2017. Altera a Consolidação das Leis do Trabalho (CLT), aprovada pelo Decreto-Lei no 5.452, de $1^{\circ}$ de maio de 1943 , e as Leis nos 6.019, de 3 de janeiro de 1974, 8.036, de 11 de maio de 1990, e 8.212, de 24 de julho de 1991, a fim de adequar a legislação às novas relações de trabalho.. Disponível em: < http://www.planalto.gov.br/ccivil_03/_ato20152018/2017/lei/l13467.htm> Acesso em: 16 mar. 2018.

. Lei no 10.406, de 10 de janeiro de 2002. Institui o Código Civil. Disponível em: < http://www.planalto.gov.br/CCivil_03/leis/2002/L10406.htm> Acesso em: 16 mar. 2018. $\overline{04 / 12 / 2006 \text {. }}$

.STJ, 3를 T., REsp 712.591/RS, rel.: Min. Nancy Andrighi, j. 16/11/2006, Dje

.STJ, 3 ${ }^{\mathrm{a}}$ T., REsp 959.565/SP, Rel. Min. Paulo de Tarso Sanseverino, ac. 24.05.2011, DJe 27.06.2011.

.STJ, 3a Turma, REsp 1.152.541-RS, rel. Min. Paulo de Tarso Sanseverino, j. 13-9-2011, DJ 21-9-2011. 
Personalidade Acadêmica Homenageada:

Carlos Aurélio Mota de Souza (Universidade Ibirapuera - UNIB) 06.09.2010.

STJ, 4ㄹ T., AG 1172750/SP, Rel. Min. João Otávio de Noronha, DJe .STJ, 4⿳亠丷厂 T., REsp 632.704/RO, Rel. Min. Jorge Scartezzini, Dj. 01/02/2006.

ANDRADE, André Gustavo Corrêa de. Dano Moral e Indenização Punitiva - 2.ed. Rio de Janeiro : Lumen Júris, 2009.

CAHALI, Yussef Said. Dano Moral - 3. ed. São Paulo: Revista dos Tribunais, 2005.

CAVALIERI FILHO, Sérgio. Programa de Responsabilidade Civil. 11 ed. São Paulo: Atlas, 2014.

COSTA, Mário Júlio Almeida. Direito das obrigações. Coimbra: Almedina, 2004.

DIREITO, Carlos Alberto Menezes; CAVALIERI FILHO, Sérgio. Comentários ao novo Código Civil: da responsabilidade civil, das preferência e privilégios creditórios. Rio de Janeiro: Forense, 2004.

ENGISCH, Karl. La idea de concrecion en el derecho y en la ciência jurídica atuales. Tradução de Juan José Gil Cremades. Pamplona: Ediciones Universidade de Navarra, 1968.

GREGORIO, Valentina di. La valutazione equitativa del danno. Padova: Cedam, 1999.

LARENZ, Karl. Derecho de obligaciones. Madrid: Editorial Revista de Derecho Privado, 1959.

LISBOA, Roberto Senise. Manual de Direito Civil, volume II: obrigações e responsabilidade civil. 3. ed. rev. atual. ampl. São Paulo: Revista dos Tribunais, 2004. Manual de Direito Civil V: obrigações e responsabilidade civil. 6. ed. rev. atual. ampl. São Paulo: Saraiva, 2012.

MARTINS-COSTA, Judith. Comentários ao novo Código Civil: do inadimplemento das obrigações. Rio de Janeiro: Forense, 2003.

MAZEAUD, Henri; MAZEAUD, Leon. Traité Théorique et Pratique de la Responsabilité Civile Délictuelle et Contractuelle. 3. ed. Paris: Recueil Sirey, 1938.

MENDONÇA, Manuel Inácio Carvalho de. Doutrina e prática das obrigações ou tratado geral dos direitos de crédito. 4. ed. aum. e atual. pelo juiz José de Aguiar Dias. Rio de Janeiro: Revista Forense, 1956, t. II, n. 478. 
Personalidade Acadêmica Homenageada:

Carlos Aurélio Mota de Souza (Universidade Ibirapuera - UNIB)

MORAES, Maria Celina Bodin de. Danos à pessoa humana: uma leitura civilconstitucional dos danos morais / Maria Celina Bodin de Moraes. - Imprenta: Rio de Janeiro, Renovar, 2003.

PONTES DE MIRANDA, Francisco Cavalcanti. Tratado de direito privado. Rio de Janeiro: Borsoi, 1959.

REIS, Clayton. Avaliação do dano moral / Clayton Reis. Rio de Janeiro, Forense, 2000.

SILVA, Américo Luís Martins da. 0 dano moral e a sua reparação civil. São Paulo: Revista dos Tribunais, 1999.

SILVA, Wilson Melo da. 0 dano moral e sua reparação. 3.ed. Rio de Janeiro: Forense, 1999.

STOCO, Rui. Tratado de Responsabilidade Civil. 6 ed. São Paulo: Editora Revista dos Tribunais, 2004.

THEODORO JÚNIOR, Humberto. Dano moral. 8.ed. revista, atualizada e ampliada. Rio de Janeiro: Forense, 2016.

VINEY, Geneviève; MARKESINIS, Basil. La Reparation du dommage corporel: Essai de comparaison des droits anglais e français. Paris: Economica, 1985.

ZENUN, Augusto. Dano moral e sua reparação. 3. ed. Rio de Janeiro: Forense, 1995. 